\title{
EL LUGAR DONDE LA LENTE SONDEA LA MEMORIA: ENTREVISTA A JONATHAN PEREL
}

POR

\author{
Guillermina Walas
}

Jonathan Perel nació en 1976, vive y trabaja en Buenos Aires. Es cineasta, investigador y docente. Cursó la licenciatura en Artes de la Facultad de Filosofía y Letras (UBA). Dicta clases en el Centro de Investigación Cinematográfica y en El Observatorio. Integrante del equipo de investigación del programa UBACyT dirigido por Ana Amado. En 2013 estrena Tabula Rasa, su tercer largometraje, en la sección Panorama del BAFICI 15 . En 201217 monumentos, su segundo largometraje, participa en la Competencia Argentina del BAFICI $14^{\circ}$. En 2010, El Predio, su primer largometraje, se estrena también en la competencia Cine del Futuro del BAFICI $12^{\circ}$. Entre sus cortometrajes se destacan Los murales (2011) y Las aguas del olvido (2013). Fue dos veces ganador del Fondo Metropolitano de las Artes, y sus películas han sido seleccionadas en diversos festivales internacionales, entre los que se destacan: FIDMarseille (Francia); Rencontres Internationales Paris/Madrid/Berlin at Palais de Tokyo; Festival Internacional del Nuevo Cine Lationamericano, La Havana (Cuba); Semana de Cine Experimental de Madrid (España); Cine//B(Chile); Festival Cinematográfico Internacional del Uruguay; FIACID Festival Iberoamericano de Cine Digital (Perú); La Sudestada, Quinzaine de culture et Cinéma Argentine à Paris (Francia). Su cine está firmemente ligado a la historia de la Argentina reciente, las políticas de la memoria y sus espacios, al urbanismo, la interpelación del monumento, desde estéticas minimalistas de aparente "no intervención", donde la cámara, sin embargo, interviene y media para hacer visibles e interpelarnos sobre los olvidos, silencios e historias alternativas que existen detrás de las fachadas oficiales o de los discursos hegemónicos de representación de la memoria colectiva.

GuilLERmina Walas: Es evidente que hay una visión de la historia (o sus diferentes versiones) que atraviesa tu trabajo, pero a la vez, al romper una tradición de representación y relato lineal, esa visión se da como un signo de pregunta para el espectador. ¿Es esa tu intención, el interrogar?

Jonathan Perel: En los modos de representación lo que está en juego es nuestra forma de entender/construir al mundo, en definitiva una posición ideológica. No creo que exista la historia con mayúscula, sino que hay múltiples historias posibles, todas ellas en 
combate, en lucha por el sentido. Entonces, me interesan más las historias alternativas, silenciadas, de las minorías, que las historias que ocupan el centro de la escena y son aceptadas como verdaderas. Pienso que el modo de representación institucional, áquel ligado a la mímesis y a la fuerte impresión de realidad del dispositivo cinematográfico, lo que hace es ocultarse a sí mismo, volver transparente/invisible su propio mecanismo productivo, para proponerse como un relato objetivo, que nos atrapa y nos respeta, ordena toda su información para su clara comprensión, y construye un espectador privilegiado. Este espectador privilegiado no recibe preguntas, sino respuestas, acabadas, cerradas, que clausuran el sentido. Este modo de representación deja fuera de escena su carácter artificial y construido, en un mecanismo de ocultamiento ideológico, que propone al mundo como algo dado e inmodificable, y no como algo construido, y por lo tanto pensable de otras múltiples formas.

La ruptura de ese modo de representación institucional, la posibilidad de construir otros cines posibles, que de maneras diversas hagan presente en la imagen a su propio mecanismo de producción, es la forma de develar aquel carácter artificial e ideológico, posiblemente construyendo un espacio de preguntas, de derivas, una apertura hacia otros pensamientos y otras ideologías. Interrogar es la forma de no aceptar lo naturalizado como única posibilidad, y de multiplicar el sentido no con el fin de volver a cerrarlo en otro sentido hegemónico, sino para habitar ese espacio incómodo y frágil de lo inacabado, de lo que está en permanente construcción. Creo que mis películas, para el espectador que se acerca a ellas en busca de construcción de memoria, lo que hacen en lugar de darle eso que espera y consolarlo, es devolverle todo el peso y la carga de hacer este trabajo de elaboración por él mismo, lo cual es también una forma-creo poderosa- de construir memoria.

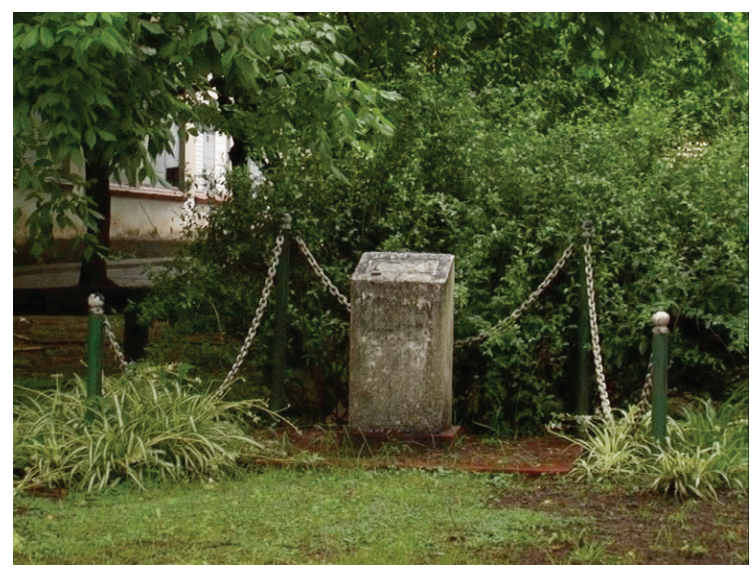

El Predio (2010)

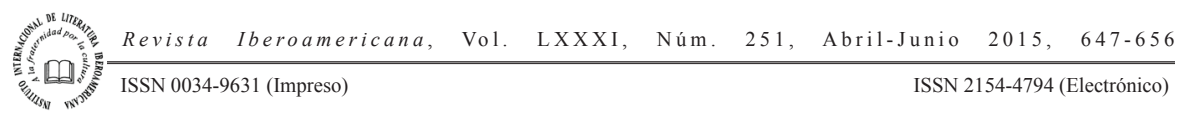


GW: En este sentido, desde El Predio (2010), pasando por el cortometraje Los murales (2011) y luego en tu segundo documental extenso, 17 Monumentos (2012), y más recientemente en Tabula rasa (2013), tu trabajo sigue una clara línea de observación de espacios claves y controversiales, traumáticos para la memoria argentina, los roles de estos espacios en el presente y sus significaciones en la tensión entre lo individual y lo colectivo. ¿Cómo comenzó tu interés por este tema de la memoria y sus lugares, sobre todo respecto de la última dictadura militar en Argentina?

JP: Soy de la generación de 1976, la de los hijos, y es un tema que atraviesa inevitablemente-también - a mi generación. En Argentina se impuso un modelo basado en los testigos directos y en las filiaciones de sangre, y mi cine viene de alguna forma a complementar eso desde un punto de vista alternativo. Que yo no sea hijo de desaparecidos es algo que suele decepcionar a la audiencia luego de ver mis películas. Pareciera no estar clara cuál es mi necesidad o mi posibilidad de acercarme a estos temas. Creo que esto es un entendimiento muy limitado de la dimensión de los crímenes cometidos, y que podría estar encubriendo pensamientos muy estrechos, aunque fuertemente anquilosados, sobre nuestra historia reciente.

Los lugares de la memoria, estos lugares de excepción, los que funcionaron como centros clandestinos de tortura y exterminio, creo que son el escenario por excelencia en donde se debate qué sociedad y qué historia estamos construyendo. Durante años estuvo prohibido el acceso a estos lugares, que ahora están siendo transformados en espacios de memoria. Eso abre muchas posibilidades y muchas preguntas, también para el cine. ¿Qué pertinencia -o no- tiene el cine en estos sitios? ¿Qué posibilidades hay para (re)construir este pasado? ¿Cómo merodear alrededor de una ausencia? ¿Cómo evitar el placer visual propio de toda experiencia cinematográfica? ¿Cómo evitar invocar lo inenarrable? Evidentemente son debates en torno a los sitios del horror que exceden al campo del cine o del arte. Pero son debates muy activos y vivos en la Argentina de hoy (al menos hasta hace un par de años), y de los cuales el arte debe participar. Mis películas aspiran a insertarse en esta discusión y a participar de estas luchas por la construcción de la memoria.

GW: ¿Qué directores o estéticas cinematográficas te han inspirado o influido en este trayecto?

JP: Así como Daney dice que fue Resnais el cineasta que lo sacó de la infancia, creo que en mi caso fue Lanzmann quien hizo de mi un niño serio. Pero no por los testimonios de Shoah, aquellos que describen el peor rostro de la humanidad, lo que el hombre es capaz de hacer consigo mismo; sino por su forma de filmar los espacios de los campos de concentración. Por esa potencia que les otorga al vacío y al silencio: donde las palabras encuentran un límite a lo decible, es la imagen la que pareciera lograr acercarnos a lo irrepresentable. El propio sobreviviente recorre lo que queda del campo de exterminio, y en su testimonio lo que quiere narrar escapa al entendimiento, incluso

Revista Iberoamericana, Vol. LXXXI, Núm. 251, Abril-Junio 2015, 647-656 ISSN 0034-9631 (Impreso)

ISSN 2154-4794 (Electrónico) 
de él mismo, admite. Es entonces que la cámara recorre en silencio, y es el espacio, las ruinas, la vegetación, el viento, el sonido del lugar, quienes pasan a participar de un relato inevitablemente lagunar, incompleto para siempre.

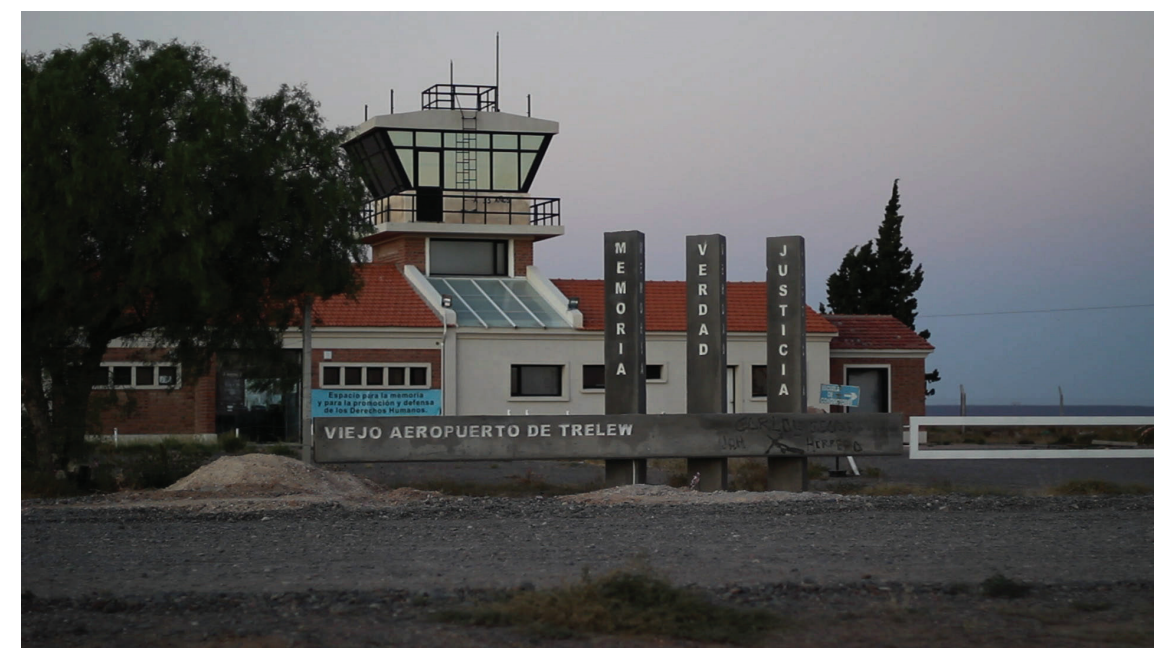

17 Monumentos (2012)

Seguramente cineastas más contemporáneos, como James Benning, Harun Farocki, Heinz Emigholz o John Gianvito son indudables referencias de mi cine. Pero lo cierto es que la verdadera dimensión significante del tiempo, su potencialidad de conectar con el pensamiento (en términos de Deleuze), la aparición de ese fragmento de tiempo en estado puro en que la duración se hace sensible, todo eso viene de Antonioni y de Ozu, los verdaderos autores que influyeron mi estética cinematográfica.

GW: Sin duda, tus filmes tienen una estética particular, donde la cámara es de alguna manera testigo de lo que sucede ante ella, aparentemente imparcial, aunque como el historiador, nunca podría serlo en su discurso. La cámara se hace presente como si fuera nuestra propia mirada subjetiva, enfocando "el hoy" alrededor de esos espacios que a su vez son considerados testimoniales y representativos de lo que Benjamin llama "la catástrofe única", los escombros que el ángel ve caer a sus pies y no puede ni detener ni recomponer porque se ve arrojado hacia el futuro (70). En el caso de Argentina esa catástrofe hoy refiere sobre todo al Golpe militar de 1976, aunque podría cubrir diversos momentos de la historia. ¿De dónde surge esa postura de la cámara, minimalista, sin aparente intervención, pero todavía enfocando en los "escombros"?

JP: Hay cosas - había escrito Rivette, nos recuerda Daney - que deben ser abordadas en el miedo y en el temblor; la muerte sin duda es una de ellas. Entro a filmar en estos 
sitios con miedo y con temblor. Son espacios que nos miran más de lo que nosotros podemos mirarlos a ellos. Lo mismo que nos pasa con una película de Hitchcock, o con los cuerpos entrelazados de Hiroshima mon amour. El desafío es cómo mirarlos en el presente. Intento hacerlo mirándolos en sesgo, a la manera de Zižek; escapando a la mirada institucionalizada o naturalizada que tenemos de ellos, para construir un punto de vista diferente, para ensayar nuevas voces con las cuales narrar, dando potencia al silencio, a lo no dicho y lo no mostrado; al vacío que otorga sentido. Renunciando a la palabra, renunciado al material de archivo, y confiando en las imágenes, en esa temporalidad suspendida que son capaces de construir, y que nos fuerzan a escuchar, a imaginar. Los escombros nos miran, nos interpelan, y hay que salir a su encuentro, a mirarlos a los ojos, a asediarlos, a conjurar los fantasmas, diría Derrida.

Creo que ese sistema estructuralista de mis películas, esa cámara minimalista, sin aparente intervención, es en verdad de una intervención máxima. La supuesta puesta en escena objetiva no debería engañarnos, se trata de un punto de vista que se hace presente en cada plano: justamente en su supuesta renuncia es que el dispositivo aparece.

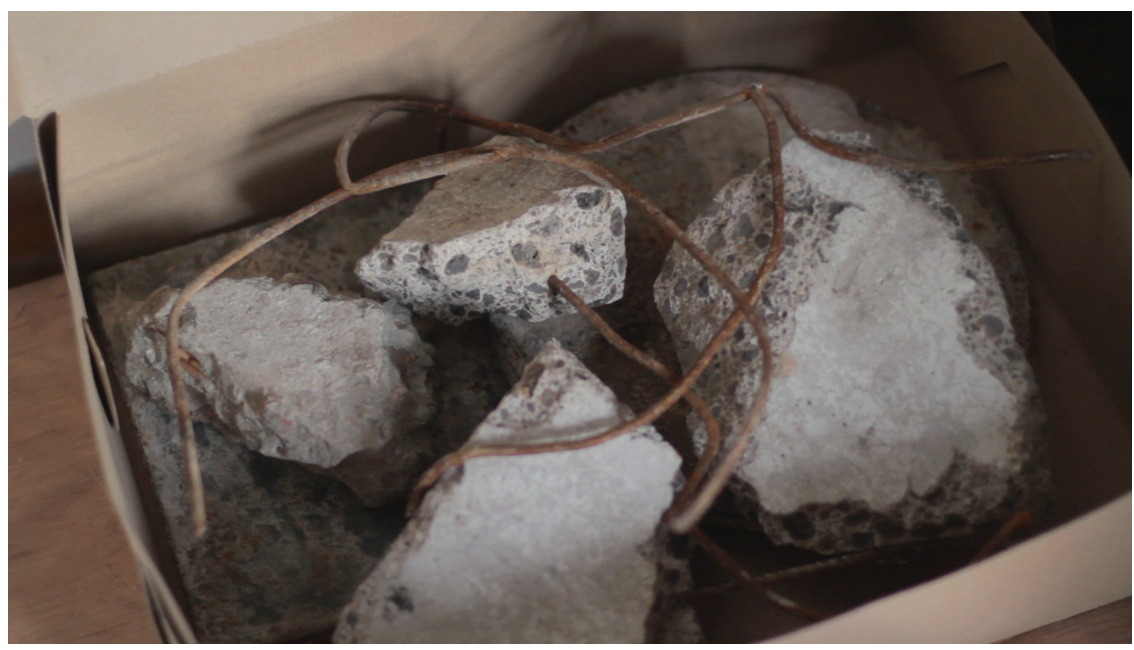

Tabula rasa (2013)

GW: Como decíamos, para el espectador, y sobre todo para el público académico, tus filmes se prestan a ser "leídos" desde o en sintonía con el pensamiento de filósofos como el ya mencionado Walter Benjamin, o como Theodor Adorno con su contundente frase sobre la imposibilidad de la poesía tras el Holocausto, y más recientemente las reflexiones de Giorgio Agamben. ¿Son éstas influencias en tu trabajo creativo o es una mera casualidad?

Revista Iberoamericana, Vol. LXXXI, Núm.
ISSN 0034-9631 (Impreso) 
JP: Son indudables influencias, porque paralelamente a mi trabajo creativo soy docente e investigador en la Universidad de Buenos Aires, y trabajo con estos temas en forma más académica en estos otros ámbitos. No creo que sea necesario evidenciar más estas influencias en mis películas, aunque Godard o Pasolini sí lo harían. Pero no son líneas de trabajo aisladas, sino que van completamente unidas, en una relación de tensión, atracción y rechazo permanente. Creo que si tuviera que definirme en alguno de estos dos campos, mi lugar está detrás de la cámara. Pero no podría hacerlo como lo hago si no tuviera esa actividad académica paralela. Preferiría no tener que definirme por uno de estos campos, sino seguir transitando en delicado equilibrio por esa cornisa incómoda que es estar en ambos al mismo tiempo.

No estaría completa la lista de influencias si no incluyéramos a artistas como Jochen Gerz o Horst Hoheisel. Son ellos quienes me iniciaron en las formas negativas de memoria, en los caminos de ruptura con las formas tradicionales que insisten sobre su propia fijeza eterna.

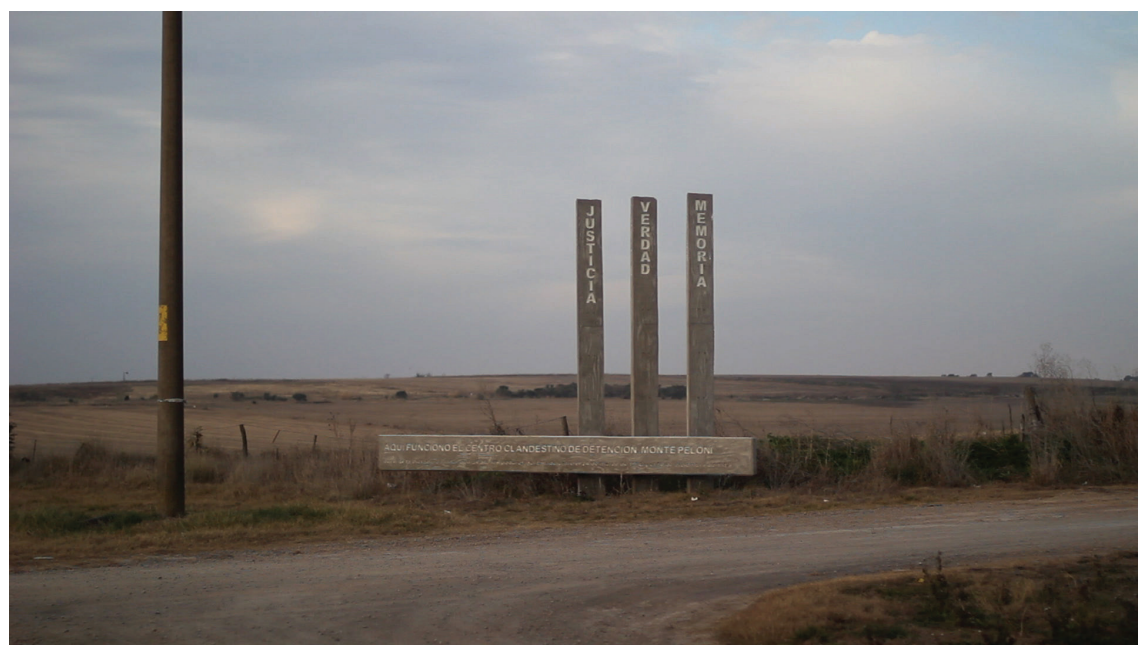

17 Monumentos (2012)

GW: ¿Qué nos puedes anticipar de tu trabajo actual y de los lugares a donde crees te llevará la cámara en el futuro?

JP: Tabula Rasa es el último largometraje que estrené en abril de 2013. Es una película que dialoga con las anteriores y sobre todo con El Predio, porque es mi regreso a la ESMA(Escuela Superior Militar de Aviación) cuatro años después de haber filmado aquella película. Esta vez para filmar el proceso de demolición del edificio conocido

Revista Iberoamericana, Vol. LXXXI, Núm. 251, Abril-Junio 2015, 647-656 
como "módulos alojamiento", aquel complejo habitacional que se veía desde la avenida Lugones o desde el tren, al pasar por la parte de atrás de ESMA entrando o saliendo de la Capital. El edificio aparentemente estaba en peligro de derrumbe, hubo un largo juicio de más de veinte años al respecto, aunque uno de sus arquitectos sigue defendiendo que las pruebas de fuerza realizadas demostraron que no existía tal peligro. De todas formas, no me resulta muy importante si el peligro de derrumbe era real o no; entiendo a la ruina como un límite, no como un espacio de libertad. Las ruinas suelen estar en peligro de derrumbe: no pareciera ser excusa suficiente para decidir demolerlas. Más allá de un cierto aprecio personal que tengo por ese edificio, primer premio de un concurso nacional y uno de los mejores ejemplos de arquitectura sistémica que hubo, me pregunto si no se podrían haber ensayado otras soluciones posibles: ¿Se lo podía reutilizar? ¿Tenía sentido dejar al menos una parte en pie? ¿Por no haber funcionado allí adentro las salas de tortura no merece ser conservado?

Esto nos conduce a otro problema, que es el de querer fijar cuáles son los límites del campo de exterminio. ${ }^{1}$ Si todo ocurrió en el Casino de Oficiales, eso limita el debate y la reflexión a ese edificio, y libera al resto del predio a la suerte de los organismos que lo van ocupando. Ciertamente fue muy interesante el debate que hubo sobre cómo tratar y narrar el Casino de Oficiales. Pero creo que circunscribir el horror a ese edificio es un intento -en vano, para nada necesario-por poner límite a aquello que no conoce bordes, aquello que se resiste a ser comprendido. Lo inquietante del campo de exterminio es que trasciende sus límites físicos, y propaga el horror al resto de la sociedad. Colombo habla de un desplazamiento del espacio concentracionario, una suerte de dislocamiento, un estar fuera de lugar. Esto mismo problematiza aquel plano final de El Predio, mirando desde adentro de la ESMA hacia afuera: vemos los autos circulando por la avenida Libertador, los edificios enfrente, los peatones que pasan. La cámara está ocupando una posición inédita para el cine argentino: ahora está adentro de la ESMA. Pero termina mirando hacia afuera: mira a la sociedad, la interroga, la invita a ingresar al espacio, a participar de los ejercicios de construcción de memoria que allí adentro se ensayan. Lo interesante de esto es no pensar al espacio como algo finalizado, con límites precisos, sino como algo inacabado, inestable, en permanente construcción, y producido como resultado de contradicciones y luchas. Esa toma final de El predio tenía un sentido posiblemente esperanzador: todo estaba por construirse en la ESMA, el espacio estaba abierto y receptivo, los debates y reflexiones estaban activos. Mi temor era que eso se institucionalizara, clausurando esa condición inacabada y "en construcción" que creo que debería persistir en un espacio de excepción como es la ESMA.

1 Planteado por Pamela Colombo en su artículo “A Space Under Construction”. Journal of Latin American Cultural Studies 21/4 (2012): 497-515.

Revista Iberoamericana, Vol. LXXXI, Núm. 251, Abril-Junio 2015, 647-656 ISSN 0034-9631 (Impreso)

ISSN 2154-4794 (Electrónico) 


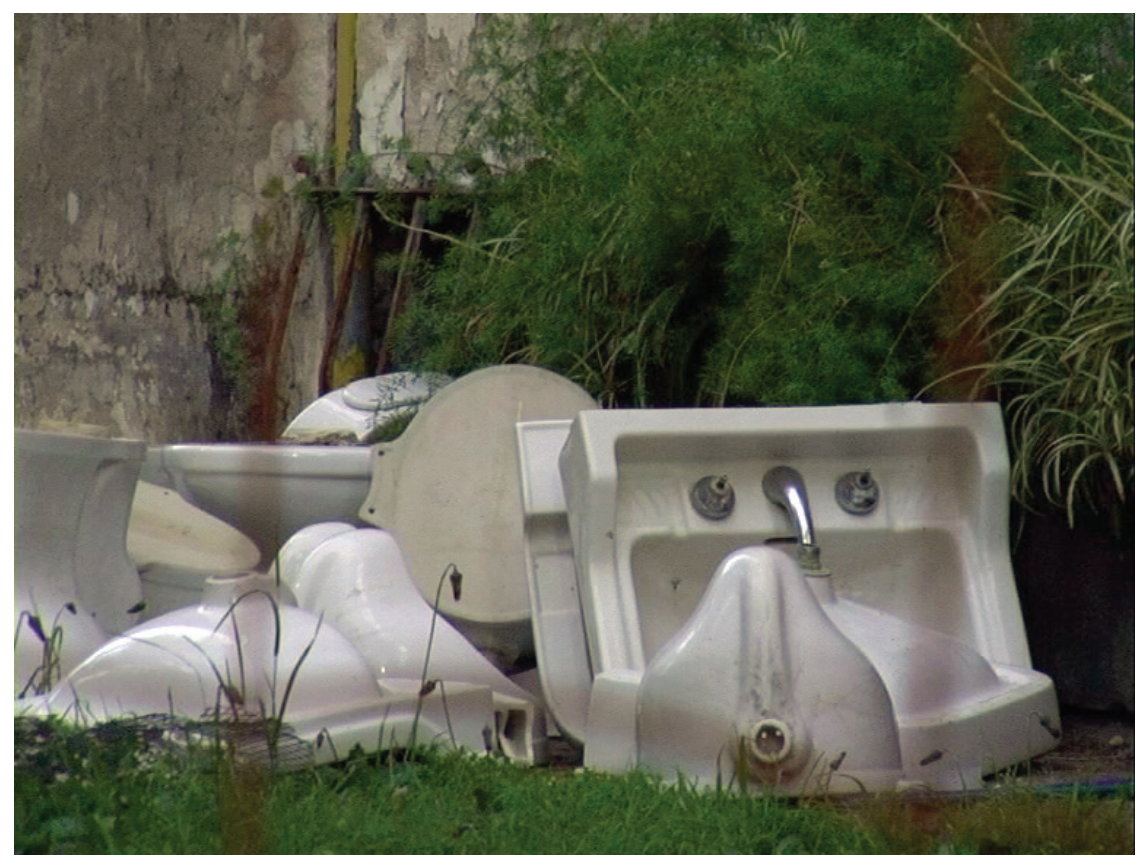

El Predio (2010)

Volviendo a Tabula Rasa, es una película en cierta medida mucho más desesperanzada respecto a la posibilidad de reflexión y debate en torno a la ESMA. Más allá de la falta de un concurso adecuado para evaluar y pensar qué hacer con el edificio "módulos alojamiento", y sobre la preocupación que me genera que se haya decidido demolerlo con tanta liviandad, lo cual me habla de cómo parecieran estar haciéndose las cosas en la ESMA; lo que más me inquieta de esta decisión -lo que me horroriza- es que en ese espacio se planea construir un Museo y Memorial de Malvinas. ¿No se podría haber construido en otro lugar? ¿Por qué adentro de la ESMA? ¿Es entonces la ESMA una Disneylandia del horror? ¿Es aún hoy la ESMAun espacio de reflexión y problematización sobre la construcción de la memoria?

Pero Tabula Rasa no termina donde pareciera terminar: en ese largo paneo de varios minutos que muestra el territorio arrasado, donde ya no queda nada de lo que alguna vez hubo (apenas los árboles, verdaderos testigos). Sino que luego de ese aparente final, viene su epílogo: los escombros archivados, conservados y filmados en mi casa como fósiles, y luego la tabula rasa del escritorio de trabajo, los ladrillitos de lego para volver a construir aquel edificio demolido; que no es otra cosa que ensayar posibles alternativas para acercarse a lo que ya no está. Es la enseñanza de Albertina Carri y sus Playmobiles. 
Luego, así como me inquieta que se haya demolido este edificio, me inquieta no poder mostrar mis películas en la ESMA; no porque yo no quiera, sino porque lo intenté muchas veces y las respuestas son elusivas. Me conformaría si me lo negaran abiertamente. Me preocupa más que ni siquiera puedan aceptar su propia incapacidad de incorporar discursos alternativos y en conflicto con su propia gestión. No me corresponde a mí destacar el mérito de estas películas, invocando los diversos festivales por todo el mundo donde participaron, los premios que ganaron, o los escritos y discusiones que generaron. Creo que la ESMA debería ser un espacio que se piensa a sí mismo constantemente, que se interese por no clausurar su propio sentido, sino por promoverlo como múltiple y diverso; que acepte sus inevitables derivas y no se aferre a sus -supuestas- certezas, que debieran ser provisorias.

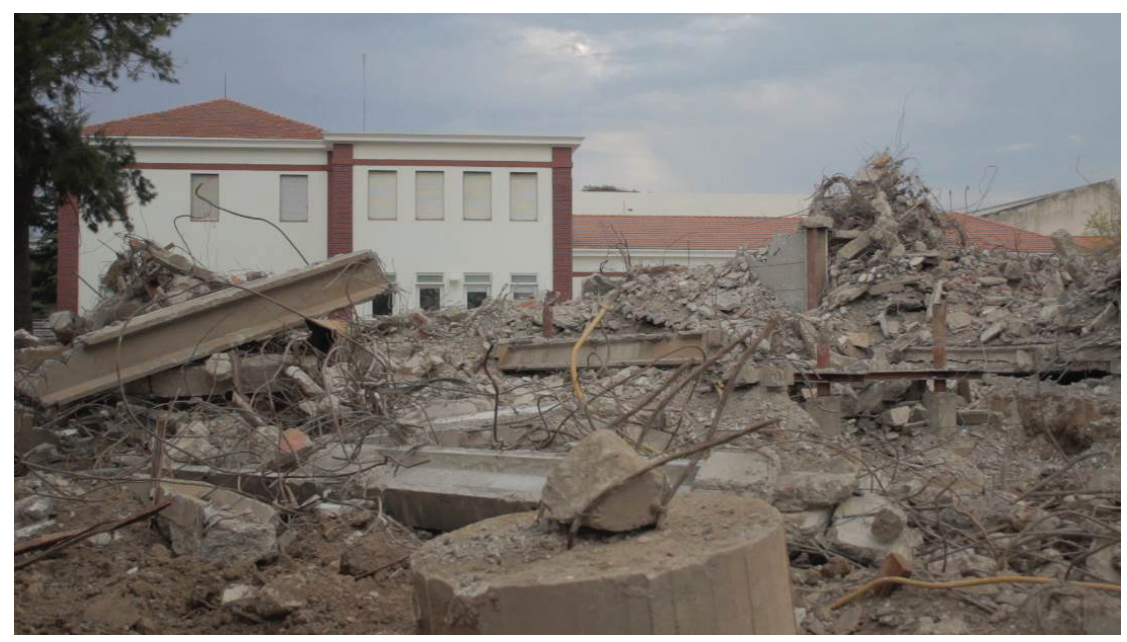

Tabula rasa (2013)

A dónde creo que me llevará la cámara en el futuro es algo incierto aún, pero eso responde a mi forma de trabajo. No sé cual será mi próxima película, pero sí confío en un cierto sistema que fui desarrollando hasta aquí, que me permite filmar en forma muy íntima y solitaria, y me da la posibilidad de salir a filmar muchas cosas -las derivas necesarias- para encontrar las películas que quiero hacer ahí afuera, en el contacto con los territorios y los materiales. Los temas en principio son cercanos a los de mis películas anteriores: estoy al mismo tiempo desarrollando una película sobre el monumento de Manchala y su inminente demolición; otra sobre los vuelos de la muerte en el delta entrerriano, suerte de road movie en barco; también una película sobre los Ford Falcons;

Pevista Iberoamericana, $\quad$ Vol. $\quad$ LXXXI, Núm. $251, \quad$ Abril-Junio $2015, \quad 647-656$
ISSN 2154-4794 (Electrónico) 
y un último proyecto que me interesa mucho sobre Campo de Mayo, que es en principio -y esto lo digo provocativamente- una película de ficción. Quizás la textura de la imagen sea documental, pero está basada en un potente texto de ficción.

Lo cierto es que todo relato es ficcional, incluso el registro documental, aunque en ciertos ámbitos -por ejemplo la ESMA- se sigue invocando una tradición documental de pretendida objetividad, que nada tiene que ver con el campo del arte y con la posibilidad que tiene el cine de re-configurar al mundo, de construirlo, participando de los discursos que luchan por darle sentido. No hay nada ahí afuera en el terreno a lo que el cine documental debiere serle fiel, todo lo que hay -lo único verdadero que existe- es la posibilidad de construir un punto de vista.

\section{BiBLIOGRAFÍA}

Benjamin, Walter. Conceptos de filosofia de la historia. H. A. Murena y D. J. Vogelmann, trads. La Plata: Terramar, 2007. 